Available online at: http:// http://tsdr.psdku.unpad.ac.id

Tourism and Sustainable Development Review Journal (TSDR)

ISSN 2722-2152 (online)

Volume 2 Number 1 (2021): 32-38

\title{
Disaster Preparedness and Risk Perception: A Study in Bandung
}

\author{
Noneng Nurjanah'1, Ali Mohamad Rezza ${ }^{1}$ \\ ${ }^{1}$ Logistic Administration, Politeknik Pos Indonesia
}

\begin{abstract}
Bandung is a city highly vulnerable to disasters (such as volcano eruption, floods). Preparation for dealing with disasters is a must to increase an effective response and reduce disaster risk. The purpose of the research is to develop a model of urban community readiness, especially the city of Bandung, in the face of impending disasters so that the factors affecting the preparedness behavior in the face of disasters. The sample for this research are 70 resident in Bandung were interviewed by using a questionnaire about adopting a set of behaviors for preparing for the disaster when it occurred. The factors identified include attitude, perceived behavioral control, subjective norm, perception of risk, and behavior. The research also collects information on social demographic factors and respondents' experiences in dealing with disasters so that the research can explain the relationship between socio-environmental characteristics adopted from the theory of planned behavior. This research provides different insights into the relationship between attitude, perceived behavioral control, subjective norm, risk perception, and disaster preparedness behavior. This research shows that risk perception has a positive impact on disaster preparedness behavior and statistically significant.
\end{abstract}

Keywords: Disaster; Risk Perception;, Behavior; Disaster preparedness behavior.

This is an open access article under the CC-BY-NC license.

\section{INTRODUCTION}

Bandung, the capital city of west java province, is located $140 \mathrm{~km}$ southeast of Jakarta and the third biggest with the largest population (bps.go.id) and the highest level of human activity in java province. Geographically, Bandung flowed by two main rivers, namely Cikapundung River and the Citarum River; Mt. Tangkuban Perahu is an active volcano experiencing volcano activities in July and August 2019. With these conditions, Bandung's city is at risk of a major natural disaster occurred (Bappelitbang Kota Bandung). These events can cause sudden catastrophic disruptions, leading to long- and short-term consequences to health and economic stability. Although it is often difficult to prepare for a disaster, individuals and communities may reduce the impact and increase the chance of a more effective response and recovery through better and more significant preparation.

A disaster is an event that destroys a community or society and causes by natural factors (natural disasters) and non-natural factors, and human factors (UNISDR, 2017). Disasters can cause

Corresponding author

Noneng Nurjanah, noneng.nurjanah@poltekpos.ac.id; Ali Mohamad Rezza, alimohamad.rezza@poltekpos.ac.id DOI: https://doi.org/10.31098/tsdr.v2i1.34

Research Synergy Foundation 
human casualties, damage to the environment, property losses, and psychological impacts (Made Irma Dwiputranti, 2019). Readiness to deal with disasters needs attention to reduce disaster risk through awareness and increased capacity to face disaster threats (Article 1 paragraph 6 of Government Regulation No. 21 of 2008 concerning the Implementation of Disaster Management). Disaster preparedness is critical for households, businesses, and communities, but many of them remain unprepared (Sutton \& Tierney, 2006). The concept of disaster preparedness encompasses measures to enhance life safety when a disaster occurs (Sutton \& Tierney, 2006). Disaster preparedness involves particular activities such as storing emergency food and water supplies, storing an essential object in a safe place, purchase any insurance against natural disasters, preparing an emergency kit for home and car, making a family emergency plan, and teach relatives what to do in case of emergency,

Disaster preparedness is behavior defined as actions that ensure resources necessary to carry out effective response are available before a disaster. Disaster preparedness behavior is preparations and adjustments such as storing water, food and clothes, preparing an emergency kit, and other activities that reduce the risk of injury and damage. The theory of planned behavior is a behavioral prediction theory that explains why individuals perform (or do not perform) particular behavior (Skurka et al., 2018), such as disaster preparedness behavior. The theory of planned behavior (TPB) is a theory that predicts behavior that can explain why individuals do and do not do certain behaviors. In the theory of planned behavior, the behavior predicting using three determinant variables: attitude, perceived behavioral control, and subjective norm (Daellenbach et al., 2018; Skurka et al., 2018; Sutton \& Tierney, 2006). According to many studies conducted on disaster preparedness, several factors affecting preparedness include risk perception (Miceli et al., 2008)

This research examines the relationship between attitude, subjective norm, perceived behavioral control, risk perception, and dan disaster preparedness behavior (Daellenbach et al., 2018; Miceli et al., 2008). The purpose of the research is to develop a model of disaster preparedness behavior, especially in Bandung. To identify the factors that influence community or behavior toward disaster preparation and each construct's role in this behavior. This study developed seven hypotheses which were then tested. The research hypothesis is :

H1. The Effect of Attitude on Perceived Behavioral Control is significant and positive.

H2. The Effect of Attitude on Risk Perception is significant and positive.

H3. The effect of Perceived Behavioral Control on Risk Perception is significant and positive.

H4. The effect of Risk perception on Disaster Preparedness Behavior is significant and positive.

H5. The effect of Subjective Norm on Attitude is significant and positive.

H6. The effect of Subjective Norm on Perceived Behavioral Control is significant and positive.

H7. The effect of Subjective Norm on Risk Perception is significant and positive.

\section{LITERATURE REVIEW}

Preparedness well knows as consisting of measures that enable individuals, households, and societies to respond effectively and recover more quickly when disasters occurred (Sutton \& Tierney, 2006). The effort also aims to ensure the availability of resources, encompass measures to 
enhance life safety, and include actions to enhance the ability to undertake emergency actions when a disaster occurs.

Attitude is defined as the degree of an individual's behavior assessment about good or bad, positive or negative behavior. Attitude toward the behavior is determined by a combination of individual beliefs regarding the positive and/or negative consequences of carrying out a behavior (behavioral beliefs) with the individual's subjective value against each of these behavioral consequences (outcome evaluation). Generally, the more individuals assess that behavior will produce positive consequences, the individual will favor this behavior. However, if individuals increasingly assess that behavior will result in negative consequences, they will tend to be unfavorable to the behavior (Ajzen, 1991). Research by Skurka et al. (2018) shows that attitude toward behavior affects behavior.

Subjective norms are a function based on normative beliefs, namely beliefs about individual approval and/or disagreement with behavior. subjective norms are perceptions individuals to pressure from the environment social to do or not to do a behavior Research by (Skurka 2018) shows that subjective norms affect behavior.

Perceived behavioral control defined as an individual's perception of the degree of easiness and problem of performing a behavior. Perceived behavioral control is determined by a combination of individual beliefs regarding supporting and/or inhibiting factors from carrying out a behavior (control beliefs), with the strength of individual feelings about each of these supporting or inhibiting factors (perceived power control). Azjen (1991) explains that Belief about supporting and inhibiting factors from carrying out behavior is based on an individual's previous experience of behavior, information that individuals have about a behavior obtained by observing knowledge possessed by themselves and others known to the individual, and also by various other factors that can increase or decrease individual feelings about the level of difficulty in carrying out a behavior.

Definition of Risk Perception is a subjective evaluation of future events' likelihood and possible material damage influenced by the event (Miceli et al., 2008; Skurka et al., 2018). The perception of risk is a complex thing, including cognitive factors and affective factors, where when an individual evaluates the possibility of a dangerous event occurring, the individual will rely on previous affective experiences, feelings, and a picture of the current state (current feelings), and images associated with events (Slovic et al., 2004).

\section{RESEARCH METHOD}

The research was conducted in Bandung and was resident of Bandung, the 10 (ten) Times Rule is referred to as a guide in determining the research sample's size (J. F. Hair et al., 2011; J. F. J. Hair et al., 2014; Joseph F. Hair et al., 2012). Based on these considerations associated with the structural pathway in the research model, it is found that the minimum sample size in this study is ten times the largest number of formative indicators used to measure one construct $(10 \times 7)$ so that the number of samples in this study can be determined as many as 70 samples. A Sampling of the target population will be carried out using the simple random sampling method with data collection techniques using questionnaires distributed online. Testing the validity of the research construct in the initial data collection using the Spearman rank method and testing the reliability of the measuring instrument intended in this study is a questionnaire with the method. Consistency 
between items using Cronbach's alpha, calculated using SPSS 20 software, and structural model using SmartPLS software.

\section{FINDINGS AND DISCUSSION}

Data use in the early stage of research has a total sample size of 30 respondents to check the research instrument's measurement model. Based on the measurement results, internal consistency is in the range of its threshold value. Convergent validity is declared good if the AVE value is above 0.05 (Fornell and Lacker, 1981). Heterotrait-Monotrait Ratio (HTMT) value is not above 0.9 (Table 2), and the CI Range does not touch the value 1, meaning that all of these variables are different from one another. All indicators are lying to be maintained. Discriminant validity can be said to be good.

Table 1. Measurement Model Result

\begin{tabular}{lccc}
\hline Variable & \multicolumn{2}{c}{ Internal Consistency } & $\begin{array}{c}\text { Convergent } \\
\text { Validity }\end{array}$ \\
\cline { 2 - 4 } & $\begin{array}{c}\text { Cronbach } \\
\text { Alpha }\end{array}$ & $\begin{array}{c}\text { Composite } \\
\text { Reliability }\end{array}$ & $\begin{array}{c}\text { Average Variance } \\
\text { Extract }\end{array}$ \\
\hline Subjective Norm & $0,6-0,9$ & $0,6-0,9$ & $>0,5$ \\
\hline Risk Perception & 0,87 & 0,91 & 0,71 \\
\hline Perceived Behavioral Control & 0,84 & 0,88 & 0,55 \\
\hline Attitude & 1 & 1 & 1 \\
\hline Disaster & 0,74 & 0,84 & 0,57 \\
\hline
\end{tabular}

Table 2. Heterotrait-Monotrait (HTMT) Ration

\begin{tabular}{lccccc}
\hline & Attitude & $\begin{array}{c}\text { Disaster } \\
\text { Preparedness } \\
\text { Behavior }\end{array}$ & $\begin{array}{c}\text { Perceived } \\
\text { Behavioral } \\
\text { Control }\end{array}$ & $\begin{array}{c}\text { Risk } \\
\text { Perception }\end{array}$ & $\begin{array}{c}\text { Subjective } \\
\text { Norm }\end{array}$ \\
\hline Attitude & & & & \\
\hline $\begin{array}{l}\text { Disaster } \\
\begin{array}{l}\text { Preparedness } \\
\text { Behavior }\end{array}\end{array}$ & 0,48 & & & \\
\hline $\begin{array}{l}\text { Perceived } \\
\text { Behavioral } \\
\text { Control }\end{array}$ & 0,37 & 0,39 & & \\
\hline Risk Perception & 0,17 & 0,33 & 0,24 & \\
\hline Sibjective Norm & 0,80 & 0,46 & 0,36 & 0,20 \\
\hline
\end{tabular}

The test results in Table 1 and Table 2 proved that the instrument's validity confirms primary data selection. The research data collection was conducted in July 2020 and showed in Table 3 . $54,1 \%$ of participants were male, and most participants were $31-30.68,4 \%$ of participants had marital status married and mostly have 1-2 children, so the household had less than five members, and $58,5 \%$ have homeownership. 
Table 3. Sample Characteristics

\begin{tabular}{|c|c|c|c|}
\hline \multirow{3}{*}{$\begin{array}{c}\text { No } \\
1\end{array}$} & \multicolumn{2}{|c|}{ Indicator } & \multirow{2}{*}{$\begin{array}{c}\text { Percent (\%) } \\
54,1\end{array}$} \\
\hline & Gender & Male & \\
\hline & & Female & 45,2 \\
\hline \multirow[t]{3}{*}{2} & Age & $21-30$ & 43,0 \\
\hline & & $31-40$ & 34,8 \\
\hline & & $41-50$ & 16,2 \\
\hline \multirow[t]{2}{*}{3} & Marital Status & Married & 68,4 \\
\hline & & Single & 31,6 \\
\hline \multirow[t]{3}{*}{4} & Number of & None & 38,8 \\
\hline & Children & $1-2$ & 45,5 \\
\hline & & $3-4$ & 14,9 \\
\hline \multirow[t]{3}{*}{5} & Home Ownership & Private Property & 58,5 \\
\hline & & Rent Contract & 15,4 \\
\hline & & Other & 26,2 \\
\hline
\end{tabular}

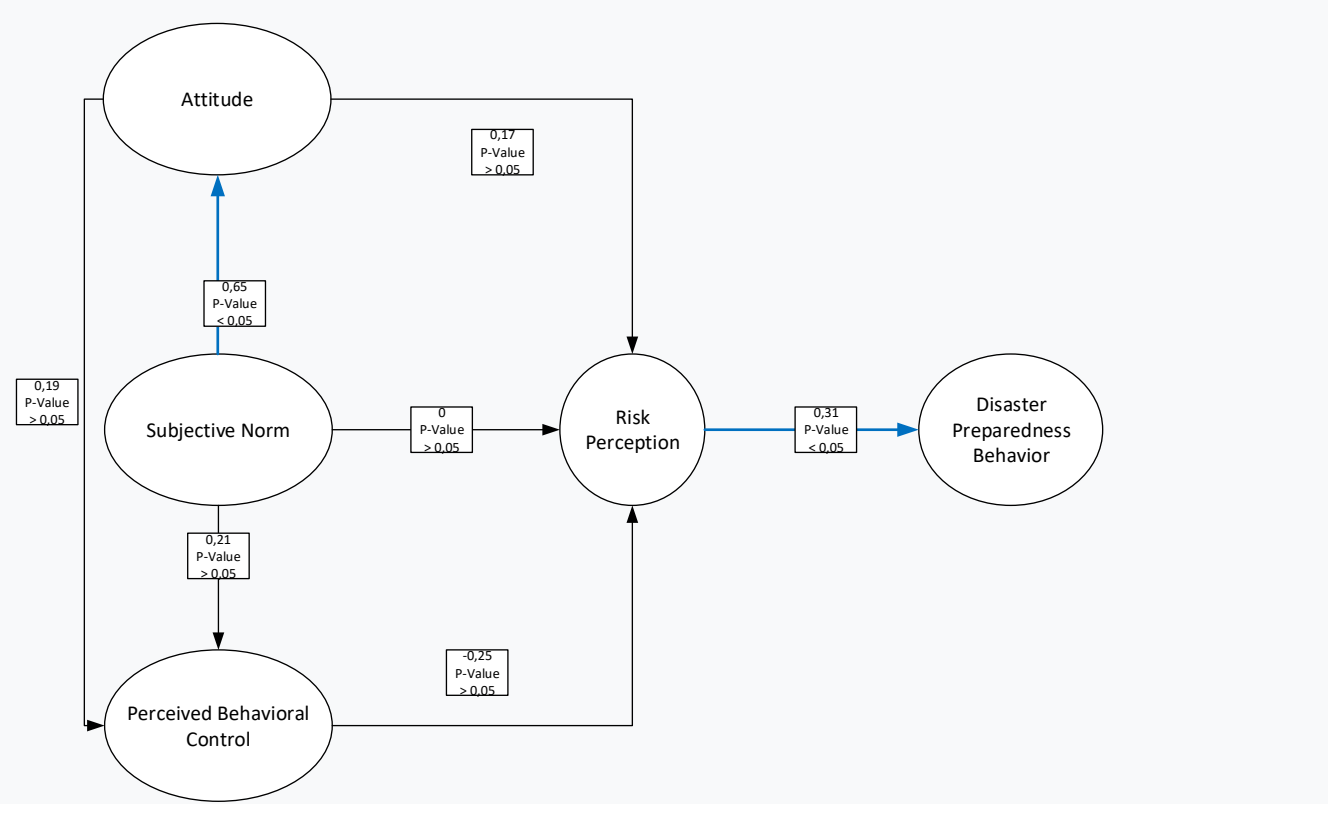

Picture 1. Path Coefficient Result

Based on the result of data processing on the structural model (Picture 1), the following result was obtained:

1. The Effect of Attitude on perceived behavioral control was positive $(0,19)$; the path relationship between attitude ? perceived behavioral control is not statistically significant (PValue $>0,05)$, so that hypothesis H1 not accepted.

2. The Effect of Attitude on Risk Perception was positive $(0,17)$.); the path relationship between attitude 2 perceived behavioral control is not statistically significant (P-Value $>0,05$ ), ), so that hypothesis $\mathrm{H} 2$ not accepted

3. The Effect of Perceived behavioral control on Risk Perception was negative $(-0,25)$; the path relationship between attitude ? perceived behavioral control is not statistically significant (PValue $>0,05$ ), so that hypothesis H3 not accepted. 
4. The Effect of Risk Perception on Disaster Preparedness Behavior was positive $(0,35)$ and the second-largest value; the path relationship between Risk Perception 0 Disaster Preparedness Behavior statistically significant ( $\mathrm{P}$-Value $<0,05$ ), so that hypothesis $\mathrm{H} 4$ accepted

5. The Effect of Subjective Norm on Attitude was positive $(0,65)$ and the largest value; the path relationship between Subjective Norm 0 Attitude is statistically significant (P-Value $<0,05$ ), so that hypothesis $\mathrm{H} 5$ accepted

6. The effect of Subjective Norm on Perceived Behavioral Control was positive $(0,21)$; the path relationship between Subjective Norm ? perceived behavioral control is not statistically significant ( $\mathrm{P}$-Value $>0,05$ ), so that hypothesis $\mathrm{H6}$ not accepted.

7. The Effect of Subjective Norm on Risk Perception was positive (0); the path relationship between Subjective Norm ? Risk Perception is not statistically significant (P-Value $>0,05)$, so that hypothesis $\mathrm{H} 7$ not accepted.

Furthermore, data processing results show the effect size value on each relationship between the two constructs. The effect size is calculated as the absolute value of each predictor latent variable's individual contribution to the latent criterion's R-square value. Effect sizes are grouped into three categories based on Kock $(2014)$ are small $(0,02)$, medium $(0,15)$, and large $(0,35)$. The effect size for each path can be seen in Table 4.

Table 4. Effect Size Result

\begin{tabular}{lcc}
\hline & Effect Size & Keterangan \\
\hline Attitude $\rightarrow$ Perceived Behavioral Control & 0,02 & Small \\
\hline Attitude $\rightarrow$ Risk Perception & 0,02 & Small \\
\hline Perceived behavioral Control $\rightarrow$ Risk Perception & 0,06 & Medium \\
\hline $\begin{array}{l}\text { Risk Perception } \rightarrow \quad \text { Disaster Preparedness } \\
\text { Behavior }\end{array}$ & 0,11 & Medium \\
\hline Subjective Norm $\rightarrow$ Attitude & 0,74 & Large \\
\hline Subjective Norm $\rightarrow$ Perceived Behavioral Control & 0,03 & Medium \\
\hline Subjective Norm $\rightarrow$ Risk Perception & 0 & None \\
\hline
\end{tabular}

This research shows that the respondent performs preparedness behavior because it views the perception of risk when disaster happens. The result of the research showed that perception of risk affects disaster preparedness behavior. Overall, these results show respondents' views about the set of probability damage if a disaster occurred and the consequences of the damage. The respondent shows disaster preparedness behavior, such as placing essential documents in a safe place and having a family plan if a disaster occurred.

The relationship between subjective norms and attitude is supported by Skurka et al. (2018), which shows that subjective norms affect behavior. French and Raven explained that social forces influence motivation to comply (Skurka, 2018) with subjective norm values about behavior. The social strength in question consists of the reward or punishment given the referral source to the individual, the individual's liking for the referral source, how much the individual considers the referral source as an expert, and the demand. Based on this statement, it can be concluded that the 
more individuals perceive that their social reference recommends doing a behavior, the individual will tend to feel social pressure to do the behavior (Ajzen, 1990).

\section{CONCLUSION \& FURTHER RESEARCH}

The research objective is constructing a model representing the relationship between the variables attitude, subjective norm, perceived behavioral control, and risk perception and their effect on disaster preparedness behavior. The result shows that the risk perception variable directly affects disaster preparedness behavior; However, the variable that impacts risk perception is not yet defined. The result shows three other variables (attitude, perceived behavioral control, and subjective norm) show no significant result. The subjective norm impacts attitude, but it can be claimed that subjective norm has an indirect impact on disaster preparedness behavior because the attitude itself does not impact.

Despite the aforementioned practical findings of the current study, several limitations must be noted. One limitation shows that the coefficient of determination shows a weak value. This shows that there is still a need to search for other exogenous variables to explain these endogenous variables better. Another limitation is that the sample size is small and needs research to be categorized based on those who have experienced and those who have not experienced disasters. It can be provided for better information about disaster preparedness behavior.

\section{REFERENCES}

Daellenbach, K., Parkinson, J., Krisjanous, J., \& Daellenbach, K. (2018). Just How Prepared Are You? An Application of Marketing Segmentation and Theory of Planned Behavior for Disaster Preparation Just How Prepared Are You? An Application of Marketing Segmentation and Theory of Planned Behavior for Disaster Preparation. Journal of Nonprofit \& Public Sector Marketing, 00(00), 1-31. https://doi.org/10.1080/10495142.2018.1452830

Hair, J. F. J., Hult, G. T. M., Ringle, C., \& Sarstedt, M. (2014). A Primer on Partial Least Squares Structural Equation Modeling (PLS-SEM). In Long Range Planning (Vol. 46, Issues 1-2). https://doi.org/10.1016/j.lrp.2013.01.002

Hair, J. F., Ringle, C. M., \& Sarstedt, M. (2011). PLS-SEM: Indeed a silver bullet. The Journal of Marketing Theory and Practice, 19(2), 139-152.

Hair, Joseph F., Pieper, T. M., \& Ringle, C. M. (2012). Applications of Partial Least Squares Path Modeling in Management Journals: A Review of Past Practices and Recommendations for Future Applications. Long Range Planning, 45(5-6), 320-340. https://doi.org/DOI 10.1016/j.lrp.2012.09.008

Miceli, R., Sotgiu, I., \& Settanni, M. (2008). Disaster preparedness and perception of flood risk: A study in an alpine valley in Italy. Journal of Environmental Psychology, 28, 164-173. https://doi.org/10.1016/j.jenvp.2007.10.006

Skurka, C., Quick, B. L., Reynolds-tylus, T., Short, T., \& Bryan, L. (2018). An evaluation of a college campus emergency preparedness intervention. Journal of Safety Research, 65, 67-72. https://doi.org/10.1016/j.jsr.2018.02.003

Slovic, P., Finucane, M. L., Peters, E., \& Macgregor, D. G. (2004). Risk as Analysis and Risk as Feelings : Some Thoughts about Affect, Reason, Risk, and Rationality. Risk Analysis, 24(2).

Sutton, J., \& Tierney, K. (2006). Disaster Preparedness : Concepts , Guidance , and Research. 